\title{
The Press Image of Community Health Nurses
}

\author{
Philip A. Kalisch* and Beatrice J. Kalisch $\dagger$ \\ *Interim Director, Center for Nursing Research, and Professor of \\ History, Politics, and Economics of Nursing, University of \\ Michigan, Ann Arbor \\ †Titus Distinguished Professor of Nursing, and Chairperson, \\ Parent-Child Nursing, University of Michigan, Ann Arbor
}

\begin{abstract}
The informational quality of press news about community health nurses is a critical factor in gaining the required public support for the scarce resources needed to advance community health nursing practice. Using content analyses, 2,561 articles on community health nursing for the period 1978-1981 were coded for key message themes and compared with articles on other nursing subjects. Results reveal that although the subject of community health nursing comprised the largest share of all clinical nursing articles, they are (1) less visible in newspapers, (2) distributed unevenly per capita among the various states, and (3) written so as to communicate low-quality information. Analysis of annual trends shows that community health nursing articles, while expanding in absolute numbers, constitute a declining proportion of nursing articles overall, and that the quality of information in current press coverage is diminishing. It is recommended that community health nurses embark on a concerted campaign to improve the quality of information carried in newspapers about their clinical specialty.
\end{abstract}

The quality of news media communications about community health nurses and the level of public opinion about the worth of the profession are inextricable. Numerous studies have pointed out that newspapers are regarded by citizens as a primary source of information. Ninety percent of adults are reported to read a daily newspaper. The Davey Report of the Special Committee on Mass Media (1977), for example, concluded,

Address correspondence to: Philip A. Kalisch, Department of History, Politics, and Economics of Nursing, $609 \mathrm{E} \mathrm{Lib-}$ erty Street, Ann Artor, Michigan 48104-2052. Telephone: (313) 7647550 .
"Newspapers are felt to be the most essential medium. ... They are the most diligent in keeping the public informed. More than any media, they are perceived to represent the public conscience." Consequently, if community health nurses are to succeed and to be taken seriously in professional and public life, it is essential that they understand better how and under what conditions the press helps set the societal agenda and what this means to and for community health nurses.

In the first place, newspapers have a direct effect in creating the subject matter that reaches the public agenda. They have an ability to start 
or keep people thinking or feeling about a given topic. Through this agenda-setting process, issues and problems become salient to the public (McCombs \& Shaw, 1972; McLeod, Becker, \& Bymes, 1974). It is interesting to note that although studies show that there is a strong correlation between press coverage and public perceptions of an issue's importance, little correlation is found between the press agenda and the actualities of the real world (Funkhouser, 1973). By just paying attention to some issues while ignoring others, the press, deliberately or otherwise, sets priorities of concern within various sectors of the public (Benton \& Frazier, 1976).

The news media also confer status and legitimacy on the persons, events, and topics reflected in their mirror. Their recognition testifies that one has arrived, that one is important enough to have been singled out from the large, anonymous masses, that one's issues and work are significant enough to deserve public notice (DeFleur \& Ball-Rokeach, 1976). Through these agenda-setting and status-conferral functions, the news media stimulate the public to perceive a fabricated "reality" about community health nurses and their work.

Historically, leaders in the profession were keenly aware of the instrumental role of the news media and effectively used the press in bringing about significant improvements in nursing and health care. Lillian Wald, for example, once convinced of an urgent cause, whether it was the provision of health care for slum dwellers, the abolition of exploitative child labor practices, the establishment of school health programs, governmental responsibility for child welfare, or the founding of a federal Children's Bureau, attempted to expand the issue to the broadest possible constituency. This involved writing letters, testifying before boards and special investigating committees, and communicating the issue to the general public through the news media. She felt that her greatest strength was in publicizing and gamering support for worthy social and health care causes (Daniels, 1977; Kalisch \& Kalisch, 1978).
Wald knew that the public and its policy makers required, at a bare minimum, a sufficient amount of valid information on which to make wise decisions pertaining to community health nursing. The urgent need to update this tradition of communicating to the public information about the effective roles and the unique contributions of today's community health nurse is self-evident. Elected officials at local, state, and federal levels set the policies that determine whether the priorities are to be roads, buildings, schools, defense, foreign aid, or community health nursing services. The taxpayers, after all, pay a large part of the cost for community health nursing. Thus if these two groups are not kept well informed, the profession will have great difficulty in securing the financial support that is essential if it is to develop its potential in meeting health care needs of the American public.

This study investigates the quality of press information about community health nurses and their services. Specific questions addressed in the study are: (1) What are the characteristics of the patterns of dissemination and levels of audience exposure about community health nurses and their services in the press? (2) What behaviors of community health nurses are being conveyed specific to their practices and their relationships with others? (3) What is the quality of the image of community health nursing that is presented in newspapers? (4) What differences exist between newspaper coverage of community health nursing and other nursing news? (5) What changes have occurred in the newspaper presentation of community health nursing over time?

\section{METHOD}

Content analysis, a research method that facilitates the specific measurement of news messages disseminated to the public about nursing, was used in this study (Krippendorff, 1980; Gerbner, 1979). This is part of a comprehensive study of the informational quality of all news about nursing.

A nationwide service is employed to clip all 
newspaper articles about nurses and nursing, with each one identified as to name, location, and circulation level of the newspaper, as well as date of publication and each article's page placement. According to the service's own estimates, they clip approximately 80 percent of the articles on any subject. To validate this premise, the project subscribed to a competing service for three months. Results of comparisons show that 73 percent of articles clipped by each service were identical. No differences were found for the variables under study.

The "News Analysis Tool," which includes sections dealing with dissemination, audience exposure, article subject, and measures indicative of the quality of nursing news, was developed and tested for use in the project. Coders are recruited and trained to apply the tool to the newspaper articles. All coders undergo a standardized training program prior to the actual coding of data. All newspaper articles are coded for the even numbered years $(1978,1980$, 1982 , etc.); for the altemate years $(1979,1981$, 1983 , etc.), a 20 percent sample is coded. Intrarater reliability is determined by comparing a given coder's current responses to randomly selected articles that he or she coded several months before. Recoding is done without access to the results of the first coding. Intrarater reliability across all coders and all items is 93 percent. Interrater reliability is determined by having all coders analyze a sample of randomly selected newspaper articles; across all coders and all items it is 94 percent.

\section{FINDINGS}

This analysis is based on 2,561 newspaper articles on the subject of community health nursing published between January 1978 and December 1981. These articles are compared with those that focus on the other clinical nursing specialties ( $n=2,441$ ) as well as with noncommunity nursing articles $(\mathrm{N}=22,621)$. Of the clinical articles ( $N=5,002)$, community health nursing represents 52.5 percent of the total while medical-surgical nursing is second with 30.8 per- cent, parent-child nursing third with 13.8 percent, and psychiatric-mental health nursing fourth with only 2.9 percent of the total (Figure 1). Articles on community health nursing account for 10.7 percent of the total number of nursing articles in the entire dataset.

As can be noted in Figures 2 and 3, while the number of articles on community health nursing did increase over the four-year span, the overall number of articles about nurses and nursing rose even more, so that the actual proportion focusing on community health nursing declined somewhat. The percentage of articles on community nursing as a proportion of the total, however, did increase from 45.5 percent to 55.4 percent (Figure 4). Thus community health nurses are gaining in their proportion of clinical news but losing in their proportion of all nursing news.

Community health nursing articles cover a variety of subjects, the most prominent ones being: (1) home care of the sick (31.2 percent); (2) health promotion (23 percent); (3) school nursing (19.7 percent); (4) combined health promotion and home care of the sick (9.6 percent); (5) family nurse practitioners (4.8 percent); (6) occupational health nursing (2.2 percent); (7) school nurse practitioners (1.6 percent); $(8)$ independent practice (1.2 percent); and miscellaneous subjects with low frequencies. Only four articles, or 0.2 percent, dealt with the topic of community health nursing consultants or specialists.

Every subject or concept goes through a life cycle of its own, starting with a growth phase, then advancing to maturity, and finally falling into decline, which may result in senescence in this case, obscurity - if actions are not taken to ensure its renewal. The press image of community health nursing is undergoing a significant change. The most important four-year trends (reflected in Figures 5 and 6) reveal that the subject of health promotion in relation to community health nurses is diminishing in importance (from 27.3 to 21.8 percent) while home care of the sick is rising rapidly to take its place (from 22.7 percent to 37.1 percent). It appears that traditional press coverage of community health 


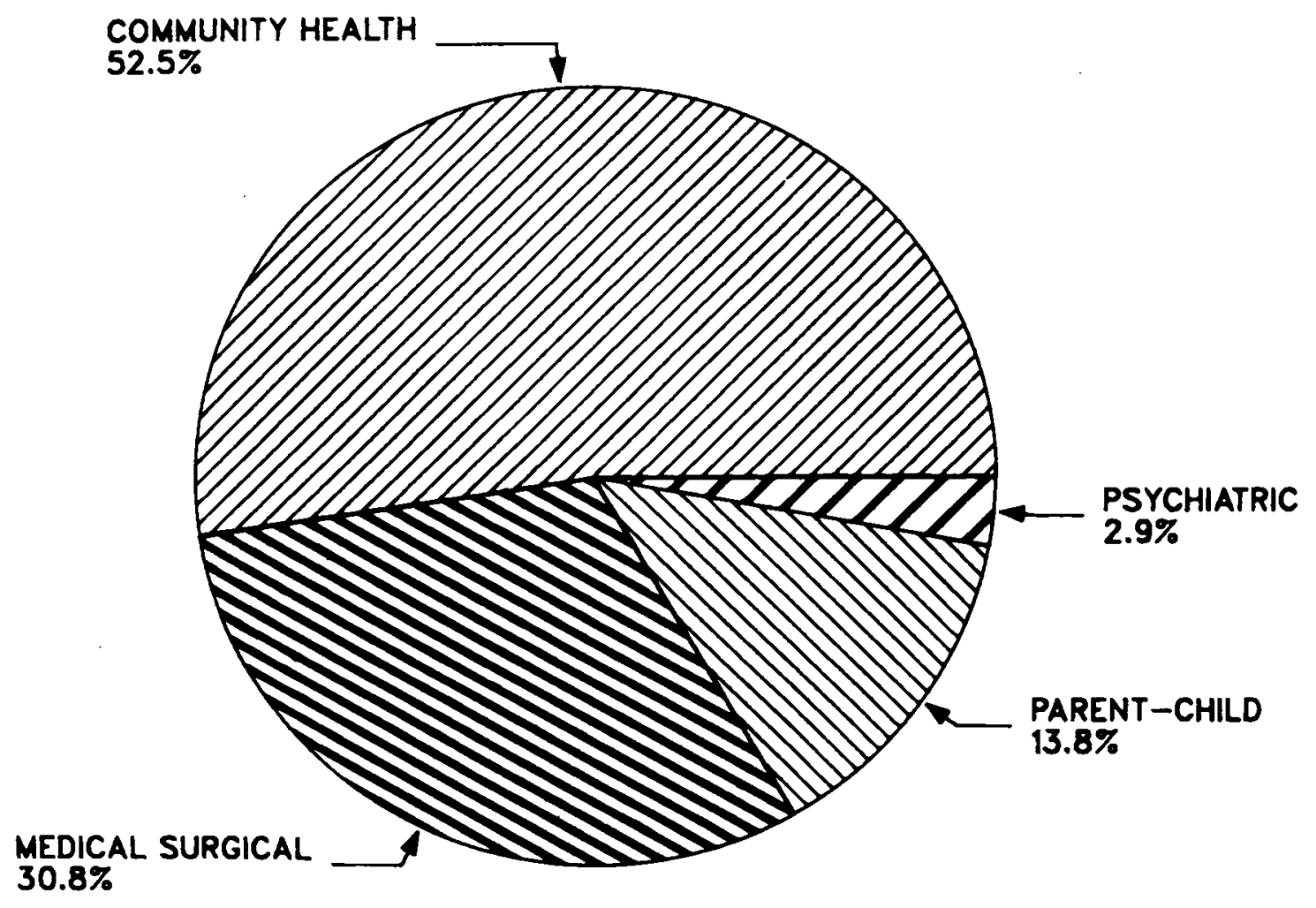

Figure 1. Clinical Nursing Specialties in Newspapers

nurses in relation to health promotion activities has reached the decline stage and will continue its downward trend if nothing is done to intervene. In addition, the number of news items about family nurse practitioners shows a sharp decline from 10.8 to 3.2 percent $\left[x^{2}(39)=\right.$ 129.5, $P<0.001]$ and those on independent practice reveal a slight decrease from 2.3 to 1.2 percent.

\section{Patterns of Dissemination and Audience Exposure}

Figure 7 displays the geographic distribution of community health nursing articles per capita by state. Seventeen states fell in the low category with a $\bar{X}$ (mean population) of 19.4 articles per state for the total four-year period, while the high category contained 16 of the states and had a $\bar{X}$ of 75.7 articles. The 10 states with the highest number of community health nursing articles per capita (from highest to lowest) are: Connecticut (46.6), Massachusetts (39.9), Missouri (39.8), Minnesota (38.7), Nebraska (27.3), Utah (24.1), Oregon (22.7), Idaho (22.3), Colorado (21.9), lowa (21.0), and New Hampshire (20.1). The ten states with the lowest number of newspaper articles on the subject of community health nursing (from lowest to highest) are: Delaware (1.1), Maryland (1.6), Rhode Island (2.4), Kentucky (2.7), Florida (3.1), Nevada (4.3), Hawaii (4.3), Michigan (4.3), Illinois (4.5), and Mississippi (4.5).

While these rankings are significant since they indicate the overall visibility (per capita) community health nursing receives in each state, it is also impoitant to compare the exposure relative to other nursing articles. Therefore a ratio of 


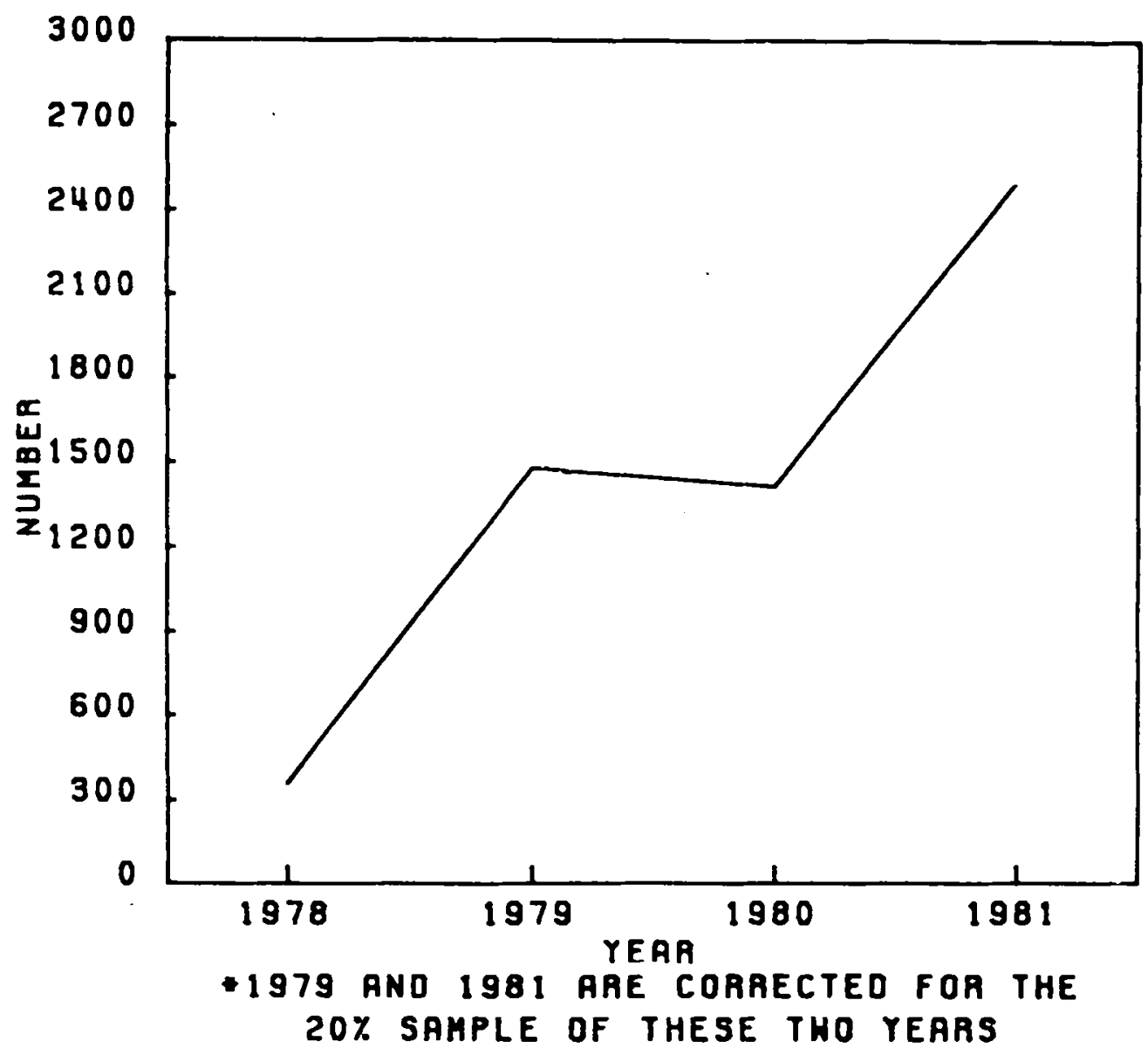

Figure 2. Number of Community Health Nursing Articles (1979 and 1981 are corrected for the $20 \%$ sample of these two years.)

articles on community health nursing to those on all other aspects of nursing articles was calculated for each state and its ranking was compared with the overall ranking. In general, the number of community health nursing articles published in a state is similar to the number generated on other nursing subjects. But several states - Connecticut, Utah, Oregon, North Carolina, Tennessee, and the District of Columbia - had much higher numbers of articles on community health nursing than on nursing overall. Apparently community health nurses in these states are doing a better job generating news than other nurses in their respective states.
Conversely, community health nurses in Delaware, Rhode Island, Alaska, South Dakota, and Wyoming are creating comparatively less news about their specialty.

Community health nursing articles are published in newspapers of lower circulation than those that focus on the other clinical subjects [t(4743) $=-12.20, P<0.001]$. This is also true for all articles $[\mathrm{t}(24040)=-18.22, P<$ 0.001 ]. Similarly, community health nursing articles appear more often than other clinical subjects $[t(4,996)=-7.47, P<0.001]$ and articles overall $[t(25138)=-16.44, P<0.001]$ in newspapers published less frequently than every 


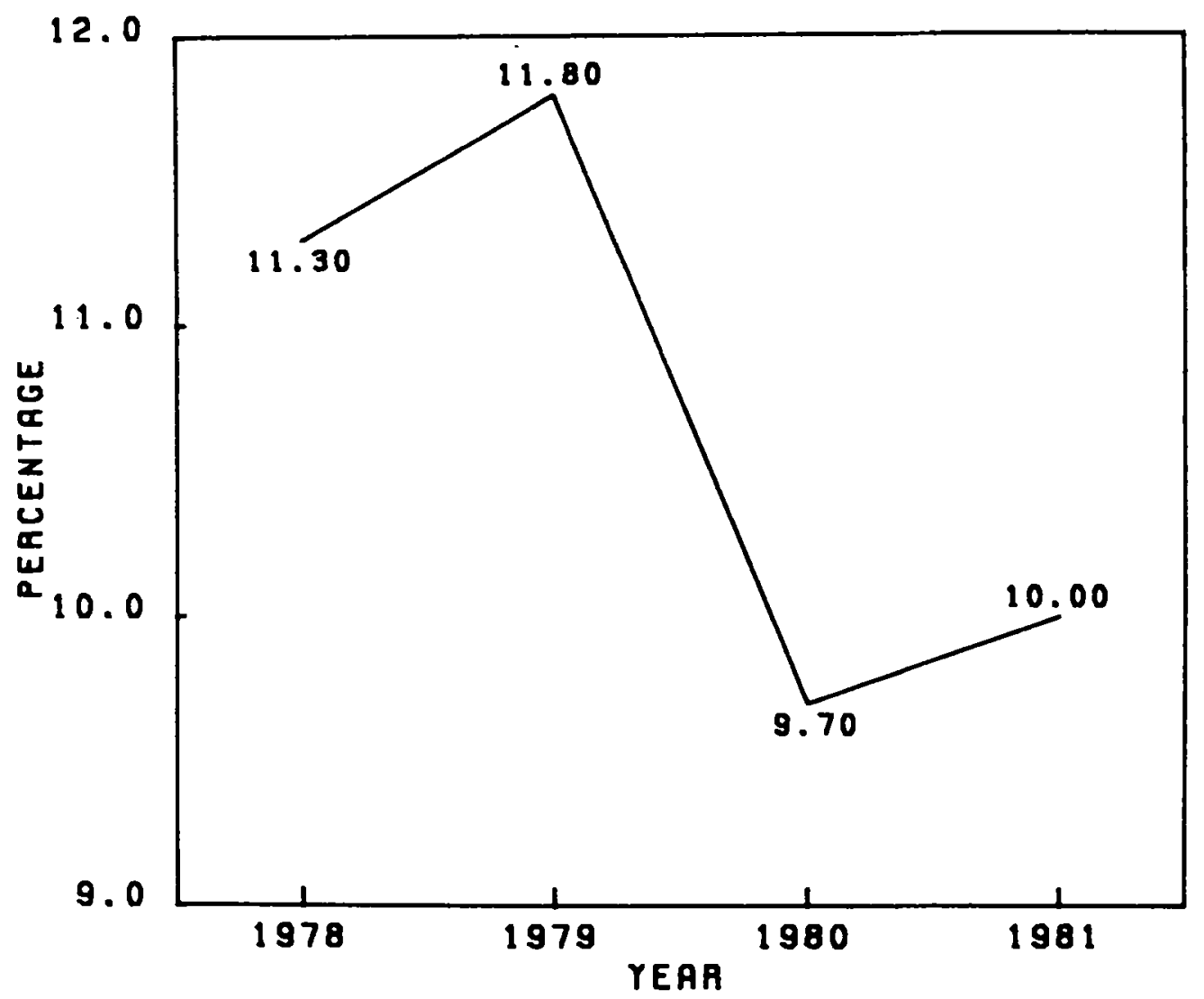

Figure 3. Percentage of Total Nursing Articles Focusing on Community Health Nursing

day. Of the total number of community health nursing articles, 54 percent are published in daily newspapers, a lower percentage than for the other clinical specialties (64 percent) and for nursing articles generally ( 70 percent). The publication frequency of newspapers with articles about community nursing dropped to an even lower level in $1980[F(3,2556)=6.05, P<$ $0.001]$.

Articles on community health nursing are less likely to be wire stories (UPI and AP) than those about the other clinical specialties $[t(5000)=$ $-2.95, P<0.001$ ] or subjects generally $[t(25174)=4.88, P<0.001]$. They are smaller (32 square inches) than other clinical stories (39 square inches) but somewhat larger than the average article (27 square inches). The size of the headlines $[\mathrm{t}(4040)=-6.40, P<0.001]$, the number of photographs $[\mathrm{t}(4040)=8.70, P<$ $0.001]$, and the size of photographs [t(4040) $=$ $-8.27, P<0.001$ ] are smaller in community health nursing articles than in those on other clinical specialties. The size of photographs $[\mathrm{t}(21367)=6.89, P<0.001]$ and the number of photographs [t $(21367)=4.60, P<0.001$ ] contained in community health nursing articles, however, are larger than those that accompany stories on nonclinical subjects. Community health nursing articles are also less likely to emphasize the nursing profession and give publicity value to nursing than other clinical articles $[t(4999)=3.6, P<0.001]$. In terms of yearly changes, no particular trends emerge for these variables. 


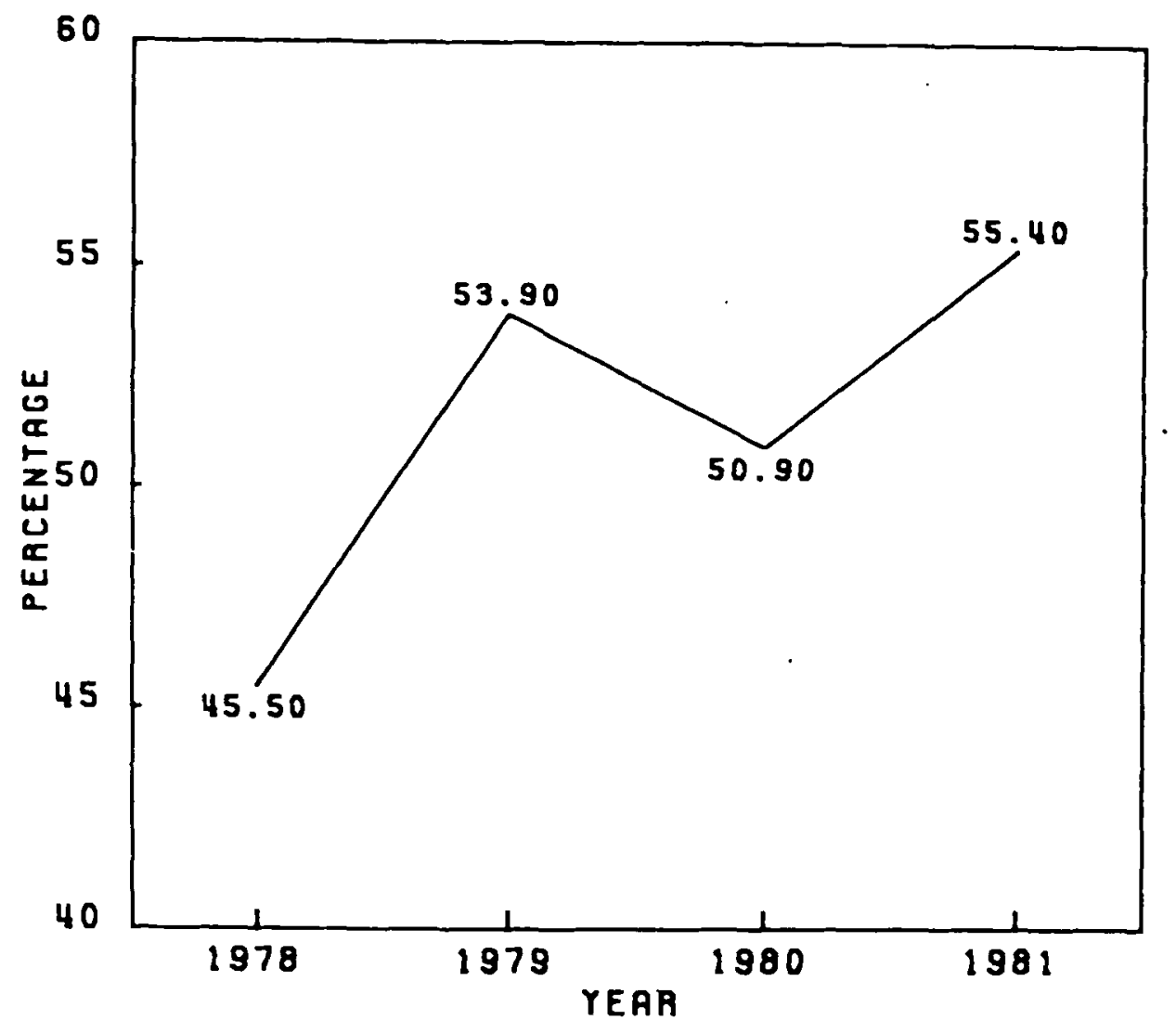

Fgure 4. Percentage of Clinical Articles Focusing on Community Health Nursing

Community health nursing articles are largely hard news (81 percent) rather than soft news (19 percent). Hard news concems events and issues that are considered urgent and vital, while soft news (also known as feature or human-interest stories) deals with issues considered interesting but without the "timely" requirement. Hard news, on the other hand, quickly becomes obsolete, while soft news can be used over a period of weeks or months. Not only are articles on community health nursing less likely to be soft news than other clinical stories $[\mathrm{t}(4578)=-9.00, P$ $<0.001$ ], the number of feature articles in this subject area has declined from 46 percent in 1978 to 3 percent in $1981[\mathrm{~F}(3,2325)=87.45$, $P<0.001$ ]. Community health nurses are less likely to write letters to the editor than other nurses [2.7 versus 5.8 percent; $\chi^{2}(2)=73.16$, $P<0.001$ ]; however, as can be seen, nurses as a whole rarely do so either.

Overall, the majority of nursing articles are written by males ( 80 percent), which is not surprising given the fact that the majority of news reporters are male. This imbalance of male to female reporters has been a consistent pattem over all of the years studied. Clinical nursing articles as a group, however, are much more likely to be written by women ( 40 percent versus 20 percent for other subjects). This finding is explained by the fact that males are overwhelmingly assigned to political, economic, and legal issues, while females are generally directed to cover social and health issues, which are basically judged to be of less importance. 


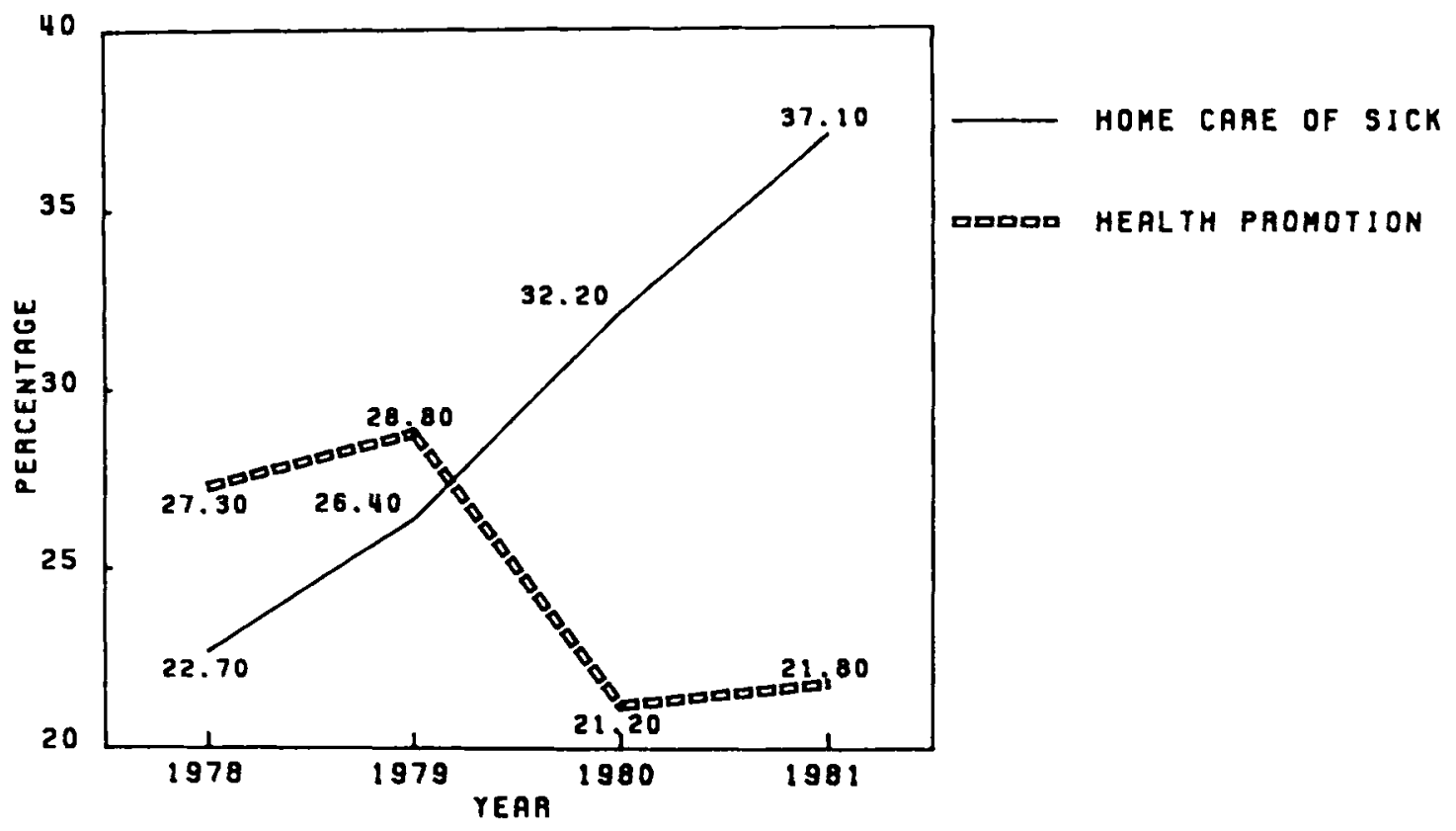

Figure 5. Community Health Nursing Content in Newspapers



Flgure 6. Image of Nursing in Newspaper Articles 

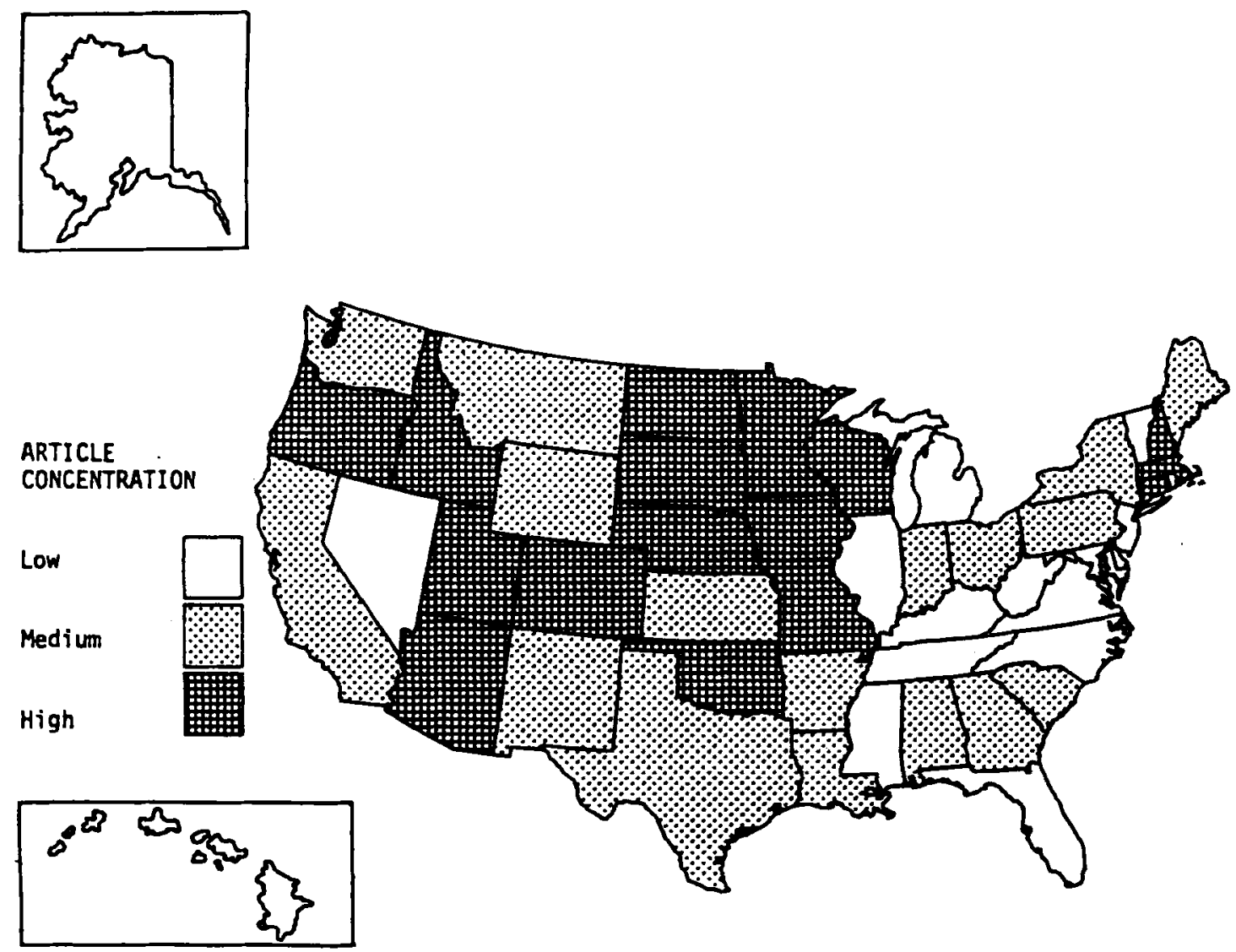

Figure 7. Community Nursing Articles per Capita

\section{Demographic Characteristics of Community Health Nurses}

Although a slight increase in the mention of men as nurses in all articles occurred over the four years, nurses are almost always shown as women in newspaper articles. Community health nursing articles prove to be least likely to include men, with only 4 percent doing so, while the other nursing specialties mention men in 9 percent of the articles $[\mathrm{t}(3716)=-5.95, P<$ 0.001 ], and overall the nursing articles include men 13.4 percent of the time $[t(16083)=$ $-11.50, P<0.001$ ]. Buttressing this strong sex-role orientation is the fact that community health nursing articles exceed those in the other clinical fields in mentioning the traditional stere- otypes of mothering and self-sacrifice as well as details about the physical appearance of nurses $[\mathrm{t}(5000)=-6.22, P<0.001]$.

Community health nurses are shown more often to have earned a baccalaureate degree as compared with nurses in the other clinical specialties or those depicted in newspaper stories generally $\left[\chi^{2}(3)=116.95, P<0.001\right]$. Community health nurses are less likely, however, to have a graduate degree than nurses in the other clinical specialties (3.9 versus 9.4 percent). Newspaper articles focusing on the clinical area of community health are more likely to include licensed practical nurses together with registered nurses giving care than are stories about the other clinical specialties $\left[\chi^{2}(8)=254.68, P<\right.$ $0.001]$. 


\section{Characteristics of Community Health Nursing Practice}

As would be expected, community health nurses are shown practicing in community settings in 95 percent of the articles, while in articles about the other clinical specialties, nurses are depicted in such settings only 15 percent of the time $[\mathrm{t}(4837)=68.09, P<0.001]$. The focus of care is preventive in 55 percent of the community health nursing articles and this is significantly higher than the other clinical specialties, which average 15 percent $[t(4504)=26.65, P<$ 0.001 ]. Although the practice setting remained constant over time, a slight downward trend is apparent in the proportion of articles emphasizing prevention $[F(3,985)=6.95, P<0.001]$.

The number of newspaper articles portraying community health nurses exceeds those devoted to the other nursing fields in depicting progressive clinical activities such as emotional support to patients and their families, expanded role functions, and patient education [ $\mathrm{t}(5000)=$ $2.28, P<0.02]$. An upward trend in the inclusion of these activities is evident $[F(3,2557)=$ $15.15, P<0.001]$. On the other hand, community health nursing articles are less likely than those about other nursing specialties to include the progressive nonclinical activities associated with administration, teaching, and scholarly work $[t(5000)=-12.25, P<0.001]$. Again, a significant upward trend in depictions of community health nurses engaged in nonclinical progressive activities is apparent $[F(3,2557)=$ 11.30, $P<0.001$ ]. Community health nurses, however, are also more likely to be shown doing traditional nursing activities (bed-making, bathing patients, etc.) than are other nurses $[\mathrm{t}(5000)$ $=2.16, P<0.05]$.

Community health nursing articles include more statements about the advantages of nurse providers over other health care providers than other clinical stories $[t(5000)=13.90, P<$ $0.001]$ or articles generally $[\mathrm{t}(25179)=61.3$, $P<0.001$ ], and community health nurses are shown to have a more positive impact on patient welfare than other nurses $[\mathrm{t}(456)=2.75, P<$
0.011 . Role confusion with physicians and other providers occurs less frequentily in articles on community health nursing than in those on the other clinical specialties $[t(3665)=-2.56, P<$ 0.01 . Community health articles show nurses in innovative roles less often, however, than the other clinical specialties $[\mathrm{t}(5000)=4.12, P<$ 0.001 ] and are more likely than other clinical $[\mathrm{t}(4040)=10.38, P<0.001]$ or articles generally $[\mathrm{t}(21366)=10.54, P<0.001]$ to include mention of inadequate funding for nursing services.

\section{Professional Relationships}

When the professional relationships of community health nurses are compared with those of nurses in other clinical areas, distinct similarities and differences emerge. Both groups are characterized as having similar relationships with one another, physicians, the government, and health care agencies. Communication between nurses and these groups is portrayed in relatively positive terms. Relationships of community health nurses with patients $[\mathrm{t}(3457)=2.19, P<0.03$, other health care providers $[\mathrm{t}(1083)=2.45, P$ $<0.01$ ], and educational institutions [t(1536) = 2.63, $P<0.01$ ] are, however, less positive than those shared by other clinical nurses and members of the above groups.

In analyzing changes over time, community health nurse relationships with nurses $[\mathrm{F}(3,115)$ $=15.22, P<0.001]$, physicians $[F(3,833)=$ $62.17, P<0.001$ ], other health care professionals $[F(3,571)=83.22, P<0.001]$, and the government $[F(3,916)=40.61, P<0.001]$ are showing a downward trend. On the other hand, relationships with educational institutions $[F(3,818)=99.39, P<0.001]$ and patients and consumers $[F(3,1749)=47.81, P<0.001]$ are becoming more positive. Community health nurse-physician relationships are more likely to be characterized as subordinate (as opposed to collegial) than nurse-physician relationships in the other specialties $[\mathrm{t}(958)=-7.19, P<$ $0.001]$ and in articles generally $[t(2182)=$ $-4.80, P<0.001$ ] 
Praise by other nurses is more frequent in community health nursing articles $[t(825)=$ $2.29, P<0.021$, and negative treatment of nurses is mentioned less often in these stories than in either other clinical $[\mathrm{t}(4040)=-5.00$, $P<0.001]$ or articles generally $[\mathrm{t}(21366)=$ $-7.66, P<0.001$ ]. Finally, community health nurses are less likely to be shown seeking power than nurses in the other clinical specialties $[\mathrm{t}(5000)=-4.57, P<0.001]$ or those described generally [t(25179) $=-23.62, P<$ 0.001 ]. What power-seeking behavior is in evidence among the community health nursing artcles is on the decline $[F(3,2557)=3.58, P<$ 0.01].

Although community nursing articles are more positive in tone than those on non-clinical subjects [t(25158) $=12.03, P<0.001$ ], there are no differences in this respect between articles on this and other clinical specialties.

\section{DISCUSSION}

The relatively large number of newspaper articles on the subject of community health nursing indicates that nurses practicing in this specialty have been much more effective in generating news than nurses in the other clinical areas. This fact is particularly noteworthy when one considers that although only 10.5 percent of all nurses (7 percent in community health and 3.9 percent in school health) are actually working in community nursing, 52.5 percent of the articles focus on it (Institute of Medicine, 1983). Yet the relative success of community health nurses could be misleading if one does not consider the fact that nurses in the other clinical areas, particularly psychiatric and parent-child nursing, have generated a minuscule number of articles on their specialties.

Aside from the quantity of articles attained, those on community health nursing do not compare favorably in terms of their visibility in newspapers. They are published in lower-circulation newspapers, appear in newspapers with lower frequencies of publication, are less likely to be wire stories, and have smaller headlines and arti- cle size as well as fewer photographs of a smaller size. They also give less visibility to the nursing profession per se than the other articles do. Furthermore, the volume of these articles is inordinately distributed among the states, with 17 states showing an average of only 19.4 articles (or 4.8 annually) on this specialty for the fouryear period. Consequently, a large proportion of the American population is offered a deficient level of information about community health nurses and their services. Even states with higher numbers of articles are not feeling the impact of the full potential of this news market.

The fact that only 10 percent of such articles are feature stories further underlines this point, since feature stories, unlike hard news, do not depend on the tight yesterday, today, and tomorrow time restrictions. We estimate that daily there are hundreds of unrealized feature story ideas on community health nursing in every city across the nation. Hard news is not reaching its full potential either, as little treatment of community health nursing is given in coverage of city, county, and state health department board meetings and budget actions.

Why is this profession underrepresented in newspapers? One reason has to do with the imbalance of nurses' power in the health care system. Nurses, who suffer from surplus powerlessness, are considered impotent by other groups, and their work is perceived as less newsworthy, especially since they do not actively seek coverage. In addition, the fact that 96 percent of nurses are female, and female socialization has placed a high value on modesty, automatically precludes news-seeking behaviors. Even the struggles of community health nurses to gain more power in health care tend to be made up of a series of small, gradual events with little immediate significance for a wider public, and consequently they do not make the press agenda. Thus nurses as potential news makers are placed in a very difficult position by the definition of news: most community health nurses are denied the decision-making power that would make their actions news, and without power and the consequent prominence, only their most obtru- 
sive actions (strikes, crime, etc.) are considered newsworthy.

Another reason for the paucity of press coverage is that nurses as a whole have failed to recognize that they have a responsibility to advance the public's knowledge of their profession. They have neglected the hard reality that public support is necessary for them to gain access to the scarce resources needed to carry out their responsibilities in health care. Of all nurses, however, those practicing in community health have been the most aware of the connection between public opinion and survival, and perhaps this accounts for their relative success in generating press attention.

In terms of informational quality, press coverage of community health nurses shows that their practice takes place almost exclusively in community settings, such as clinics and patients' homes, where they largely provide direct care that results in a positive impact on client welfare. They are shown to have more education, engage in a greater number of progressive clinical activities, praise each other more, and mention the advantages of nurses as health care providers. On the negative side, articles are less likely to include: (1) males as nurses, (2) administrative and scholarly activities, (3) nurses in innovative roles, and (4) power-seeking behavior. Also negative are the findings that these articles are more likely to include: (1) traditional stereotypes of mothering and self-sacrifice, (2) LPNs giving nursing care, (3) traditional nursing activities, and (4) negative relationships with patients/ consumers, educational institutions, and some health care professionals. Community health nurses are also shown to be more subordinate in their relationships with physicians, a surprising finding given the autonomous nature of their practice.

Analysis of annual trends in the depiction of community health nurses in newspapers shows a large increase in numbers of related articles, but this finding must be qualified by the fact that the number of these articles is declining as a proportion of the total. On the positive side, community health nurses are engaging in more progressive professional activities over time, but the other significant trends all have a negative connotation. Community health nursing articles show a decrease in the number of feature stories. As each year progresses, they also contain fewer actions indicative of power-seeking behavior by nurses and less preventative care and health promotion activities. Furthermore, relationships with other nurses, physicians, other health care professionals, and the govemment are all becoming more negative. Even though relationships with patients and educational institutions are improving, they were more negative initially than those described in stories about the other clinical specialties.

The weight of these data leads to the conclusion that the quality of information contained in articles about community health nursing is much lower that it should be. Even more important is the fact that the press image of the community health nurse is moving away from the progressive, innovative, powerful, and preventiononiented profile it historically held toward a more traditional, passive, and restoration-oriented presentation. One cannot help but conclude that community health nurses have not fully used newspapers to demonstrate adequately the diversity and importance of their work.

The task at hand is obvious. Community health nurses must work collectively and individually to put themselves and their issues before the general public by way of the press and to ensure that the informational quality of news about their specialty and their newspaper image are reflective of the realities of their practice, education, and research (Kalisch \& Kalisch, 1983). Some of the uneasiness that has characterized the relationship between community health nursing and the news media must yield to the recognition of the power of newspapers to serve sound health interests if they are supplied with appropriate information and assisted in the difficult task of translating the language of the profession into the language of the lay public. Community health nursing issues will not be ac- 
corded high priority in our society until newspapers cover them as thoroughly and as prominently as they do competing issues.

\section{ACKNOWLEDGMENT}

This study was supported by research grant NU00881, "Informational Quality of Nursing News," from the U.S. Public Health Service, Health Resources Administration, Division of Nursing.

\section{REFERENCES}

Benton, M., \& Frazier, P. J. (1976). The agendasetting function of the mass media at three levels of informational holding. Communication Research, 3, 261-274.

Daniels, D. (1977). Lillian D. Wald: The progressive women and feminism. (Doctoral dissertation, City University of New York, 1977). Dissertation Abstracts Intemational, 39. (University Microfilms no. 77-11, 171).

DeFleur, M., \& Ball-Rokeach, S. (1976). Theories of mass communication (3rd ed.). New York: David McKay.
Epstein, L. K. (1978). Women and the news. New York: Hastings House.

Funkhouser, G. R. (1973). The issues of the sixties: An exploratory study in the dynamics of public opinion. Public Opinion Quarterly, 37, 62-75.

Gerbner, G. (1979). The analysis of communication content. New York: John Wiley.

Institute of Medicine, Division of Health Care Services. (1983). Nursing and Nursing Education: Public Policies and Private Actions. Washington, DC: National Academy Press.

Kalisch, P., \& Kalisch, B. (1978). The advance of American nursing. Boston: Little, Brown.

Kalisch, B., \& Kalisch, P. (1983). Improving the image of nursing. American Joumal of Nursing, 83(1), 48-52.

Krippendorff, K. (1980). Content analysis. Beverly Hills: Sage

McCombs, M., \& Shaw, D. (1972). The agendasetting function of the media. Public Opinion Quarterly, 52, 15-22.

McLeod, J. M., Becker, L. B., \& Bymes, J. E. (1974). Another look at the agenda-setting function of the press. Communication Research, 1, 131-166.

Special Committee on Mass Media. (1977). Report of the Royal Commission on violence in the communications industry (Vol. 3). Toronto: Queen's Printer for Ontario. 